\title{
DOSSIÊ: Políticas de Avaliação Externa e a Questão da Qualidade da Educação no Brasil
}

\section{APRESENTAÇÃO}

\author{
Maria Simone Ferraz Pereira ${ }^{2}$ \\ Universidade Federal de Uberlândia
}

A Revista Educação e Políticas em Debate publica, no presente número, o Dossiê: Políticas de Avaliação Externa e a Questão da Qualidade da Educação no Brasil. Esta edição foi organizada em um contexto social extremamente difícil, em virtude da pandemia do Coronavírus (Covid 19) ou Sars-CoV-2, a qual tem produzido efeitos nefastos para a saúde pública, em escala mundial, ocasionando infecções e mortes na maioria dos países do globo³. No Brasil, em decorrência das medidas de isolamento social, muitas instituições de ensino foram fechadas como forma de mitigar os efeitos da pandemia, sendo que, algumas estão funcionando com atividades remotas. Assim, nesse momento em que as parcas conquistas em prol da qualidade da educação podem ser comprometidas acentuando ainda mais as desigualdades estruturais do sistema educacional brasileiro, apresentamos um Dossiê com o objetivo de refletir sobre as políticas de avaliação externa e a questão da qualidade da educação, tema extremamente importante, sobretudo, nesse período em que a qualidade da educação pode ser ainda mais influenciada pelas diferenças sociais, econômicas e culturais dos estudantes e das suas famílias.

Sabemos, ainda, que o termo qualidade é permeado por diferentes concepções, por isso faz-se necessário que o mesmo seja histórica e socialmente contextualizado. De acordo com Enguita (1997, p.95),

\footnotetext{
${ }^{1}$ A temática do Dossiê tem nos acompanhado ao longo de nossa trajetória formativa e constituído campo de pesquisa. Boa parte dos aspectos abordados nessa apresentação se fazem presentes nas reflexões realizadas na pesquisa de doutorado (COSTA, M. S. F. P. M. Avaliação Institucional no Ensino Fundamental: a participação dos estudantes. Tese: Doutorado em Educação. Faculdade de Educação, Universidade Estadual de Campinas. Campinas, SP: ‘s.n. $], 2012$ ).

2 Doutora e Mestre em Educação pela Unicamp. Professora da Faculdade de Educação da Universidade Federal de Uberlândia, com atuação na graduação e na Pós-graduação, membro da linha Estado, Política e Gestão da Educação. E-mail: msimonefp@gamil.com. Lattes: http://lattes.cnpq.br/3381781135088677. Orcid https://orcid.org/0000-0001-7009-7571.

${ }^{3}$ Atualmente, países e territórios se dividem basicamente em três fases: número de infectados em alta, pandemia estabilizada e casos novos em queda. Hoje, segundo os dados disponíveis de 160 localidades no mundo, o primeiro grupo tem 75 países e territórios, sendo a maioria do hemisfério Sul, principalmente de regiões como América Latina, África e Oriente Médio. O segundo grupo, com 52, inclui lugares como os Estados Unidos, que têm o maior número de mortos e infectados, mas superaram o primeiro pico de casos de covid-19, e o terceiro, 43. Mas esse cenário muda todos os dias (Fonte: disponível em https://www.bbc.com/portuguese/brasil53047836. Acesso em 29/06/2020.
} 
Se existe hoje uma palavra em moda no mundo da educação, essa palavra é, sem dúvida, "qualidade". Desde as declarações dos organismos internacionais até às conversas de bar, passando pelas manifestações das autoridades educacionais, as organizações de professores, as centrais sindicais, as associações de pais, as organizações de alunos, os porta-vozes do empresariado e uma boa parte dos especialistas, todos coincidem em aceitar a qualidade da educação ou do ensino como objetivo prioritário ou como um dos muito poucos que merecem consideração.

Mas e nós, profisisonais da educação, o que defendemos quando afirmamos que a escola precisa ensinar com qualidade? Como tratamos uma política que tem como finalidade a premiação de instituições de ensino, mediante desempenho dos estudantes? Os índices alcançados pelas escolas nas avaliações externas conseguem evidenciar de fato que a instituição desempenhou um trabalho de qualidade? Ou, além da média alcançada os profisisonais da educação necessitam de melhores condições de trabalho, de salários dignos? As instituições precisam de profissionais comprometidos com o desenvolvimento de um projeto pedagógico, que se organize para ensinar e formar os estudantes numa perspectiva de emancipação social?

Em um momento de tantas incertezas os questionamentos se acumulam e nos convocam a refletir sobre os aspectos que impactam diretamente a realidade das diferentes instituições de ensino, de seus sujeitos e da qualificação do trabalho desenvolvido no interior das escolas. Por outro lado, faz-se necessário que os profisisonais da educação, pesquisadores consigam "recuperar a capacidade de indignação frente ao que está posto e expressar algum movimento que se oponha à inércia e ao conformismo" (FREITAS, et al., 2009, p. 70), aspectos presentes nas diferentes reflexões realizadas no dossiê.

Pensar os impactos das políticas de avaliação externa na relação com a qualidade educacional é também se opor, principalmente, à naturalização da forma como a escola tem se organizado historicamente para contribuir com a formação dos estudantes que, cotidianamente, frequentam a escola, especialmente a pública. Em relação aos estudantes, queremos que consigam responder às questões dos testes nas avaliações externas, consequentemente, elevando os índices das escolas, ou que, além de se apropriem de fato dos conhecimentos científicos sob responsabilidade da escola, saibam pensar, compreender o mundo em que vivem, entender suas amarras sociais e, assim, se organizem por melhores condições de estudo, formação e vida? Em meio a tantos questionamentos reafirmamos as ideias defendidas por Dourado, Oliveria e Santos,

Os conceitos, as concepções e as representações sobre o que vem a ser uma Educação de Qualidade alteram-se no tempo e espaço, especialmente se considerarmos as transformações mais prementes da sociedade 
contemporânea, dado as novas demandas e exigências sociais, decorrentes das alterações que embasam a reestruturação produtiva em curso. (DOURADO; OLIVEIRA; SANTOS, 2007, p. 03)

Acreditamos que precisamos discutir ou rediscutir, em cada unidade de ensino, questões que fortaleçam a luta por um ensino público diferente do que temos vivenciado ao longo de nossa história educacional e, para isso, é necessário que saibamos o que queremos para a formação das novas gerações, o que elas pensam sobre este processo e, especialmente, como podem contribuir para melhorá-lo.

Em uma sociedade pautada em princípios que ocasionam a exclusão social, lutar e defender o direito dos estudantes da escola pública aprenderem com qualidade e se formarem na perspectiva da emancipação social, muitas vezes, soa como "utopia" perante a lógica meritocrática que norteia políticas educacionais de cunho neoliberal, especialmente a política de avaliação externa.

A questão da qualidade, então, se incorpora à agenda do debate educacional no contexto das reformas educativas, caracterizadas como neoliberais. Reformas influenciadas por agências multilaterais - Banco Mundial, UNESCO (Organização das Nações Unidas para a Educação, a Ciências e a Educação), ONU (Organização das Nações Unidas) e outras num contexto de controle, de restrição de políticas sociais e de privatização. (CARREIRA; PINTO 2007, p. 10)

A concepção de qualidade se materializou nas políticas de avaliação externa, implementadas pelo governo nos últimos 30 anos e tem regulado a escola de forma a provocar, em seus profissionais, a busca obsessiva dos índices que definem se a escola é ou não de qualidade e, quase sempre, os distanciado da reflexão sobre o seu papel ante a formação dos estudantes.

Essa lógica avaliativa tem contribuído para disseminar uma concepção meritocrática de qualidade e naturalizado o que Gentili (2005) e Freitas (2005a) afirmam ser uma concepção unilateral para participar deste processo e responder às questões que são pautadas externamente à escola, pelas políticas apresentadas, de um modo desinteressado, mostrando bons resultados, independente das condições em que são produzidos. Acreditamos que a busca obsessiva de índices contribui para definir, de fora pra dentro, um padrão de qualidade que contraria a luta por uma educação socialmente referenciada.

$\mathrm{O}$ crescente protagonismo da avaliação não pode ser compreendido à margem da natureza das políticas públicas e educacionais contemporâneas, nem, mais especificamente, à margem do papel e redefinição do Estado em contexto de globalização. Inicialmente impulsionada pela emergência de governos neoconservadores e neoliberais, há duas décadas e meia, a 
avaliação tornou-se obsessiva e unidireccional, quer pelo facto de continuar a manter a sua presença de forma relativamente indiferente à natureza de governos de outras orientações político-partidárias quer pelo facto de continuar a contribuir para maximizar as funções de controle e de legitimação, em vez de apoiar mecanismos democráticos de prestação de contas e de responsabilização (accountability) mais congruentes com a promoção de justiça social e educacional. (AFONSO, 2009, p.11)

Essa vertente ancora-se num mecanismo de indução da melhoria da escola via premiação, castigo ou exposição pública dos resultados, desempenhando os sistemas de avaliação papel de destaque na regulação da qualidade. Assim, os sistemas de avaliação passaram, nas últimas três décadas, a alinhar, modelar e expressar o produto necessário a ser perseguido pelas redes de ensino e suas respectivas escolas, desempenhando, grande poder de indução.

No Brasil, o ápice desse processo foi a criação do Ideb. Adquirindo cada vez mais visibilidade, este indicador tem se tornando um modelador dos resultados desejáveis da educação brasileira e o elemento definidor das políticas que induzem o comportamento das redes para melhorar o Ideb, por meio da melhoria da proficiência das crianças e adolescentes, principalmente em matemática e linguagem.

O Índice de Desenvolvimento da Educação Básica (Ideb) foi criado em 2007 para medir a qualidade de cada escola e de cada rede de ensino. O indicador é calculado com base no desempenho do estudante em avaliações do aluno e em taxas de aprovação. Assim, para que o Ideb de uma escola ou rede cresça, é preciso que o aluno aprenda, não repita o ano e frequente a sala de aula.

Para que pais e responsáveis acompanhem o desempenho da escola de seus filhos, basta verificar o Ideb da instituição, que é apresentado numa escala de zero a dez. (...) O índice é medido a cada dois anos e o objetivo é que o país, a partir do alcance das metas municipais e estaduais, tenha nota 6 em 2022 - correspondente à qualidade do ensino em países desenvolvidos (BRASIL, 2007).

Desde sua criação, o Ideb tem sido utilizado como indicador essencial à medição da qualidade das instituições de ensino e tem regulado políticas e práticas nas diferentes redes e, principalmente, os currículos. Concordamos que os estudantes precisam melhorar sua proficiência em matemática, em linguagem e que a reprovação na escola precisava diminuir. Entretanto, qualidade restrita ao alcance de um indicador, em nossa concepção, é limitada, perigosa e pode induzir políticas e práticas tendenciosas e danosas. Dentre eles, destaca-se a redução dos objetivos educacionais em que a ação da escola se concentra na busca da melhoria das proficiências em linguagem, matemática e de melhoria do fluxo, por meio do Ideb, ocasionando o ranqueamento entre melhores e piores escolas. "A consequência de toda essa prática é que os estudantes podem ser capazes de passar no teste, mas não conseguem passar 
em um teste do mesmo assunto para o qual eles não tenham praticado. Eles dominam métodos de realizar testes, mas não o assunto em si” (RAVITCH, 2011, p. 181).

A perspectiva meritocrática, presente nas políticas de avaliação externa, tende a intensificar a desigualdade, quando optam por premiar escolas com melhores Idebs e penalizar as piores, consequentemente, entre realidades educacionais, muitas vezes, já desiguais aumenta-se o "apartheid educacional” (GENTILI, 2005, p. 41).

Com isso, escolas que desenvolvem seu trabalho em condições adversas são exigidas e obrigadas, independe da realidade, a demonstrar um padrão específico de qualidade. Padrão este definido por testes estandardizados e que impõe às instituições educacionais uma accountability, ou seja, a prestação de contas objetiva, imparcial, exata, rigorosa e quantificável dos resultados almejados.

É esta visão social que também embasa as "soluções" propostas pela engenharia da reforma empresarial na educação. Pensando na escola como uma "empresa", as escolas de menor qualidade devem sucumbir às de maior qualidade, sendo fechadas; os estudantes de menor desempenho devem sucumbir aos de maior qualidade, sendo barrados em sucessivos testes; os professores de menor qualidade devem sucumbir aos de maior qualidade, sendo demitidos. Tal como na "empresa", os processos educativos têm que ser "padronizados" e submetidos a "controle". (FREITAS, 2018, p.28 e 29).

Com tal abordagem os sistemas de ensino, as escolas, os professores, os estudantes são responsabilizados pelos resultados obtidos, independente das condições concretas de produção destes. Ainda nessa lógica, a responsabilização individual e autoritária encontra-se intimamente associada à noção de meritocracia e se concretiza por meio da avaliação, que, ao induzir a competição e a classificação, valores presentes na sociedade capitalista, contribui para acentuar as desigualdades sociais. Na concepção de Afonso:

O Estado vem adotando um ethos competitivo, neodarwinista, passando a admitir a lógica do mercado, através da importação para o domínio público de modelos de gestão privada, com ênfase nos resultados ou produtos dos sistemas educativos. [...] Nesse sentido, por exemplo, diminuir as despesas públicas exigiu não só a adaptação de uma cultura gestionária (ou gerencialista) no setor público, como induziu a criação de mecanismos de controle e responsabilização mais sofisticados. A avaliação aparece assim como um pré-requisito para que seja possível a implementação desse mecanismo (AFONSO, 2000, p. 49).

Nessa perpspectiva, a ideia do mérito, presente na sociedade capitalista em seu todo, defende como natural o fato de as pessoas serem diferentes e, por isso, terem ganhos econômicos e culturais também diferentes, maior ou menor ascensão social em função do seu esforço e da sua capacidade, ou seja, do seu mérito. Quando políticas avaliativas definem 
qualidade pelo alcance de um índice e induzem as escolas a perseguir, obsessivamente, este índice para, assim, não serem penalizadas nem culpabilizadas, elas colaboram para acentuar no âmbito da escola a naturalização de desigualdades educacionais e sociais.

Se cada turma é uma turma, se cada escola é uma escola, se cada sistema é um sistema, então, como aceitar passivamente a lógica perversa de qualidade imposta pelas políticas de avaliação? O que isto tem provocado nos profissionais da escola? Quem mais perde neste processo?

Do ponto de vista político, temos um debate em torno da questão da avaliação, ao mesmo tempo, necessário e complexo para ser feito, pois está intimamente relacionado à questão da qualidade educacional, e esta, por sua vez, se compromete com a defesa de um projeto de sociedade que pode acentuar ou não as desigualdades socioeducativas.

Temos o desafio de criar alternativas de qualidade, que expressem uma concepção de educação capaz de fazer a polarização com essa lógica simplificadora, restrita ao viés mercadológico presente nas políticas de avaliação externa. Assim, nesse contexto em que a regulação vertical e autoritária tem incidido fortemente sobre escolas, redes e sistemas de ensino, precisamos construir uma contrarregulação (FREITAS, 2005) e, assim, implementar processos em que a ideia de indução da mudança se efetive por meio da participação do poder público e dos sujeitos locais da escola. Acreditamos que contrarregulação "não é a mera obstrução ou um movimento de "fechar as fronteiras da escola" com relação às políticas centrais, penalizando o usuário do sistema público" (FREITAS, 2005b, p. 912), mas um movimento de:

[...] construção de respostas alternativas à qualidade educacional que
contrariam a lógica meritocrática, de tratamento dos resultados como
produtos descontextualizados, mais preocupados em medir do que em
interpretar as relações entre essas medidas e o contexto social em que as
escolas se encontram inseridas. (COSTA, 2018, p. 62)

Nesse sentido, ampliar as reflexões sobre as amarras presentes na política de avaliação externa e defender a necessidade de políticas e práticas avaliativas comprometidas com a qualidade para além de um índice constitui um exercício de contrarregulação, que encerra elementos essenciais para se pensar uma alternativa via avaliação que incorpore ideias importantes, em prol da qualidade educacional, e que não estão presentes nos modelos hegemônicos.

De tal modo, a avaliação tem como princípio a ideia de que a mudança é uma construção local, e não uma transferência de padrões e normas de um centro gestor para a periferia, aqui entendida como as escolas. Por isso, a mudança não pode acontecer por treinamento, nem tampouco exportada de países cujas redes educacionais sejam consideradas 
mais desenvolvidas. Assim, a qualidade educacional tende a se concretizar, se as ideias forem apropriadas pelos sujeitos envolvidos com o processo, ou seja, se for construída localmente com as restrições e possibilitadores próprios de cada realidade.

Para se concretizar a mudança na escola, em prol de sua melhoria e do desenvolvimento pleno dos estudantes, faz-se necessário reunir todos os responsáveis: famílias, alunos, funcionários, professores, gestores e poder público, para analisar a realidade, identificar seus problemas, qualificá-los, debater, pensar alternativas. Enfim, reunir todos os envolvidos para, assim, promover o debate e a apropriação local de quais são os problemas centrais da realidade educacional e suas possíveis melhorias.

As crianças precisam de uma escola pública de boa qualidade. E a resposta a este chamamento social não pode prescindir da participação dos atores da escola. A saída é aprender a avaliar de um modo que nos faça sentido e assim, desestabilizar a cultura avaliativa que nos desconforta, pela proposição de uma outra alternativa (SORDI, 2009. p. 11).

É importante destacar que, o conceito de responsabilização por pressão presente na regulação posta pela política de avaliação externa concebida na lógica neoliberal, tem gerado práticas que se distanciam da qualidade efetiva. Nesse ponto de vista, vislumbramos a necessidade do fortalecimento de uma avaliação que trabalha com o conceito de responsabilização participativa em que todos os sujeitos externos e internos, que fazem a escola, podem participar no processo de pactuação desta qualidade.

Nessa acepção, a Avaliação Institucional Participativa - AIP pode se constituir como possibilitadora de uma lógica avaliativa que se posiciona contrária à pressão de um segmento sobre outro e prevê, fundamentalmente, a negociação objetiva, clara e comprometida em encontrar localmente um caminho para a mudança, capaz de promover no plano micro a melhoria do processo de ensino e, no macro, da formação dos estudantes.

A aprendizagem da avaliação institucional implica aprender a participar, aprender a se vincular com um projeto coletivo e aceitar as "dramáticas do uso de si” para ampliar as chances de êxito de um projeto que não se curva ao instituído simplesmente. [...] A aprendizagem da avaliação institucional inclui o saber posicionar-se diante dos dados oferecidos pela avaliação externa, usando-os para esclarecer a realidade escolar, quer pela aceitação das evidências ou pela refutação das mesmas'. (SORDI; LUDKE, 2009, p. 26)

Em outras palavras, enxergamos na AIP a possibilidade de um projeto educacional de relocalização da escola e de mobilização de seus sujeitos para sua melhoria, cuja questão motivadora passa, prioritariamente, pela responsabilidade ética com a formação de crianças, adolescentes e jovens, que, dentro da escola pública, não podem ficar à mercê do descaso e 
da desresponsabilização do poder público, dos profissionais da escola e demais responsáveis pela formação da juventude.

Se quisermos garantir às novas gerações uma escola pública com um ensino de qualidade, precisamos nos comprometer com as políticas educacionais que dialogam com aqueles que são os mais prejudicados e/ou beneficiados por esse ensino. Precisamos, ainda, na condição de poder público, escola e profissionais da educação, nos comprometer com uma geração que necessita ser atendida naquilo que é responsabilidade de uma educação que se coloca de maneira intransigente na defesa ao direito dos estudantes aprenderem, na defesa por uma formação que transcende a demonstração de um índice que define um padrão de qualidade.

Qualidade nessa ótica, precisa ser direcionada para a garantia das crianças aprenderem numa perspectiva de emancipação socioeducacional. Entretanto, reafirmamos a necessidade de que se estabeleça um acordo, uma negociação entre todos os sujeitos, da comunidade escolar ao governo, para que, assim, todos se comprometam coletivamente com a mudança local e com a melhoria da educação escolar. Acreditamos que, "no novo mundo da responsabilização, a aquisição das habilidades e conhecimentos que os estudantes necessitam para terem mais educação e para o mundo do trabalho é secundária” (RAVITCH, 2011, p. 181).

A defesa de uma avaliação que conclama a todos para participar coletivamente da mudança local, diretamente comprometida com a emancipação dos estudantes que frequentam a escola pública, não pode ser entendida na mesma lógica da responsabilização vertical e autoritária presente na política de avaliação externa. Não pode, ainda, soar como desresponsabilização do poder público ou como culpabilização dos sujeitos da escola por seu fracasso. Também não pode ser compreendida como mais uma pressão para que os sujeitos da escola decidam se envolver com seus problemas e, consequentemente, buscar soluções.

Em nenhuma parte do esquema de responsabilização federal existem mensurações ou indicadores da diligência, esforço e motivação dos estudantes. Eles frequentam a escola regularmente? Eles fazem seus deveres de casa? Eles prestam atenção em aula? Eles estão motivados? Esses fatores afetam a performance de sua escola tanto ou mais que as habilidades dos seus professores. [...] Da mesma forma, os autores da lei esqueceram que os pais são primariamente responsáveis pelos comportamentos e atitudes de seus filhos. São as famílias que garantem ou não que seus filhos compareçam regularmente à escola, que eles tenham boa saúde, que eles façam seus deveres de casa e que sejam encorajados a ler e aprender. Mas aos olhos da lei, a responsabilidade da família desaparece. (RAVITCH, 2011, p. 185-186)

Parece-nos, pois, que lutar por um ensino público que leve em conta as necessidades de formação de estudantes não significa aceitar a ideia de que a escola tem poder para 
corrigir todas as mazelas sociais. Significa, portanto, que precisamos ter clareza dos nossos objetivos, das decisões que tomamos, dos projetos que norteiam nosso fazer e que prescindem de explicações para os fracassos presentes em nosso trabalho, no sentido de reduzir impactos sobre a (de)formação das várias crianças, adolescentes e jovens que, cotidianamente, frequentam a escola pública, pois:

Nem tudo o que importa pode ser quantificado. O que é testado pode em última análise ser menos importante do que o que não é testado, como a habilidade de um estudante de encontrar explicações alternativas, levantar dúvidas, buscar o conhecimento por conta própria e pensar de forma diferente. Se nós não valorizarmos os nossos individualismos, perderemos o espírito de inovação, imaginação, investigação e divergência que tem contribuído poderosamente para o sucesso de nossa sociedade em muitos diferentes campos. (RAVITCH, 2011, p. 252)

No bojo dessas reflexões, reafirmamos a necessidade de nós, profissionais educação, especialmente da escola pública, nos mobilizarmos para resistirmos aos desmontes que a educação tem sofrido nos últimos anos. Se “optarmos” pela não compreensão dos impactos dessa lógica em nossas vidas, sofreremos ainda mais as consequências das pressões feitas pelas políticas de responsabilização vertical e autoritária, ainda que elas soem como práticas lineares, mais cômodas, menos trabalhosas e, por isso, de mais fácil aceitação entre os profissionais da educação. Em tempos de tantos ataques, como resistir? Quais as condições concretas de resistência?

Acreditamos que existem várias possibilidades de resistência e que a organização de um dossiê, com a contribuição de diferentes profisisonais da educação discutindo concepções e pesquisas sobre a política de avaliação externa e a questão da qualidade, constitui uma das formas de resistência, pois disponibiliza para estudantes, pesquisadores, profissionais da educação de diferentes áreas e lugares, um conjunto de artigos que contribuem para ampliar o debate sobre a temática. Compõem o dossiê uma entrevista e 13 artigos.

A entrevista, intitulada "A centralidade da avaliação no contexto atual e o dilema da qualidade da escola pública: limites, desafios e alternativas”, traz a concepção sobre a relação qualidade e avaliação, da professora Mara De Sordi, que é professora Associada da Faculdade de Educação da Unicamp, coordenadora do Laboratório de Observação e Estudos Descritivos (Loed), da Unicamp, um laboratórico que tem se dedicado aos estudos da avaliação educacional. Na entrevista a pesquisadora, com sua vasta experiência no campo da avaliação, reflete sobre a multidimensionalidade da avaliação e sua centralidade para a consolidação da qualidade da escola pública. 
$\mathrm{O}$ artigo, "Qualidade e avaliação: influências e significados na educação brasileira", de autoria de Regiane Helena Bertagna, da Universidade Estadual Paulista "Júlio de Mesquita Filho" (Unesp) e de Liliane Ribeiro de Mello, professora da Prefeitura Municipal de Campinas, faz uma reflexão sobre os discursos políticos oficiais brasileiros sobre a qualidade da educação evidenciando que a partir de 1990, as avaliações de sistemas se constituíram como possibilidade para regulação da qualidade educacional, influenciada por organismos internacionais. Para a realização da pesquisa as autoras utilizaram do levantamento documental e bibliográfico (abordagem qualitativa) sobre a política nacional de avaliação no Brasil e as orientações do Banco Mundial para o setor educacional. As reflexões esclareceram sobre as ideias, os valores propagados e subjacentes à qualidade, impregnados da lógica do mercado, apontando para a importância da disputa de outras ideias e valores que encaminhem para a construção da qualidade social da educação, com vistas a formação humana e o direito à educação pública de qualidade.

$\mathrm{O}$ artigo, "A Hegemonia das avaliações externas e a noção de qualidade que permeia a política de educação integral do Estado de Pernambuco", de autoria de Thamyrys Fernanda Cândido de Lima Nascimento, da Universidade Federal de Pernambuco e Katharine Ninive Pinto Silva, da mesma instituição, é resultante de uma dissertação de mestrado e tem como objetivo apresentar algumas reflexões sobre a centralidade das avaliações externas na Política de Educação Integral do Estado de Pernambuco - PEI. Para a realização da pesquisa as autoras realizam uma análise documental, revisão bibliográfica e análise de conteúdo das entrevistas realizadas com professores, gestores e coordenadores pedagógicos que atuam em escolas de Pernambuco. Os resultados indicam que no PEI há um processo de introjeção dos mecanismos de cobrança que advém da gestão por resultados, que estabelece mecanismos rígidos de avaliação e responsabiliza os docentes.

$\mathrm{O}$ artigo, "Educação como prática democrática versus monitoramento da qualidade da educação em Minas Gerais”, de autoria de Abelardo Bento Araújo, do Centro Federal de Educação Tecnológica de Minas Gerais, é um recorte de uma tese de doutorado em que se analisou a política de monitoramento da qualidade da educação em Minas Gerais, tendo como referência a natureza do trabalho educativo no âmbito da economia política aplicada à educação. $\mathrm{O}$ artigo abordou uma questão específica que emerge em fragmentos das falas dos sujeitos: indícios da negação da condição de sujeito daqueles que realizam a educação no dia a dia da escola - profissionais da educação e alunos. O autor constatou que os índices permitem contrapor a educação, como prática que necessita ser democrática, e a avaliação externa, pois a educação tem como função promover a condição de sujeito. 
$\mathrm{O}$ artigo de Solange Pereira da Silva, da Universidade Federal do Pará, intitulado " $O$ processo de avaliação externa nas séries iniciais: indicadores de qualidade ou regulação do trabalho docente" apresenta a sistematização de um estudo acerca da avaliação externa nas séries iniciais e seus indicadores de qualidade ou de regulação do trabalho docente. O estudo foi realizado, por meio da análise de documentos, de aplicação de questionário e de entrevista. A autora concluiu que, com os resultados da avaliação externa, pode-se colocar em dúvida o resultado do comprometimento docente no interior da escola dependendo do resultado, com possibilidade de constrangimento, de comparações e de manipulação da política de financiamento.

O artigo de Katia Eleotério Rubio, da Rede Municipal de Monte Mor e Geisa do Socorro Cavalcanti Vaz Mendes, da Universidade Estadual de Campinas, intitulado “ $A$ avaliação externa na perspectiva de docentes do ensino fundamental em uma escola municipal do interior paulista" é um recorte de uma pesquisa de mestrado em que se buscou compreender a avaliação externa na perspectiva de docentes do $1^{\circ}$ ao $5^{\circ}$ ano e sua influência no trabalho pedagógico em uma escola municipal paulista. As autoras recorreram ao estudo documental, à legislação e à entrevista semiestruturada. Além disso, pesquisaram os dados da rede municipal disponibilizados pelo Inep (2009 a 2017). Nas reflexões realizadas as autoras identificaram as influências da política de avaliação externa na prática pedagógica, configuradas nas categorias: responsabilização vertical; busca por melhores resultados da escola/professores por meio de simulados e de treinamento das crianças; e o estreitamento curricular para atender o que se avalia (mede) nas avaliações externas.

$\mathrm{O}$ artigo, "Qualidade e avaliação externa: relações estabelecidas por Orientadores Pedagógicos e Professores de quatro escolas da Rede Municipal de Ensino de Campinas”, de autoria de Luana Ferrarotto, do Instituto Federal de Educação, Ciência e Tecnologia de São Paulo aborda a relação entre qualidade e avaliação externa em larga escala a partir das vozes de Orientadores Pedagógicos (OPs) e professores de quatro escolas da Rede Municipal de Ensino de Campinas (RMEC). Para a realização da pesquisa a autora entrevistou OPs e docentes de escolas com diferentes cenários de enraizamento da política de Avaliação Institucional Participativa, existente na RMEC desde 2008. A autora conclui que para os entrevistados a qualidade do trabalho desenvolvido pela instituição não pode ser conhecida, integralmente, pelos resultados obtidos em avaliações externas e que não foi possível perceber, ainda, uma análise ampliada da qualidade da escola, na perspectiva da qualidade social.

$\mathrm{O}$ artigo, "Formação docente no contexto da política de avaliação externa: narrativas de professores do $2^{\circ}$ ano do ensino fundamental", de autoria de Genira Fonseca de Oliveira, da Rede Pública 
Estadual do Ceará e da Universidade Estadual do Ceará, Giovana Maria Belém Falcão, da Universidade Estadual do Ceará e Eunice Andrade de Oliveira Menezes, da Universidade Federal do Cariri, teve por por objetivo compreender como a formação no PAIC reverbera na prática de professores do $2^{\circ}$ ano do ensino fundamental. De acordo com as autoras, os pressupostos da Psicologia Histórico-Cultural orientam a investigação, de natureza qualitativa, com suporte no método (auto) biográfico, a partir das narrativas de professores. Segundo as autoras, os investigados reconhecem as contribuições da formação em suas práticas docentes, principalmente, por possibilitar um direcionamento de suas ações, embora esta se caracterize por orientações prescritivas. Por fim, afirmam que a garantir de uma formação que favoreça a autonomia, a reflexão e que considere o contexto, permanece como desafio para programas de formação docente.

$\mathrm{O}$ artigo, "O Enem como instrumento de autoavaliação: um projeto não efetivado", de Vitor Sergio de Almeida, da Universidade do Estado de Minas Gerais, reflete se a proposta de autoavaliação (olhar para si) feita por meio do Exame Nacional do Ensino Médio (Enem) encontra ressonância com a realidade dos discentes. Para a realização da pesquisa o autor fez documental e bibliográfico. Segundo o autor, os achados da pesquisa evidenciam que não há uma política curricular difundida pelo governo a fim de embasar o professor e o aluno acerca da disseminação da autoanálise. Tal prática, aliada ao referido exame, é conduzida (quando existe condução) de modo acrítico. Por fim, constata que a autoavaliação necessita de um contexto mais humanizado e pessoal, ao contrário do cenário competitivo e meritocrático desencadeado por outras atribuições do Enem.

$\mathrm{O}$ artigo, "Programa de avaliação seriada da Universidade de Brasília: lições para a avaliação do ensino médio", de autoria de Sidelmar Alves da Silva Kunz, do Instituto Nacional de Estudos e Pesquisas Educacionais Anísio Teixeira, Remi Castioni, da Universidade de Brasília e Gilvan Charles Cerqueira de Araújo, da Secretaria de Estado de Educação do Distrito Federal e da Universidade de São Paulo, abordaram a trajetória histórica da experiência do Programa de Avaliação Seriada da Universidade de Brasília (PAS) e as suas contribuições para a avaliação do ensino médio no Distrito Federal. A partir das análises teóricas, bibliográficas e documentais, assinalaram que, por meio da compreensão das parametrizações avaliativas de tendência global e o histórico de construção do PAS, foi possível detectar um inventário de elementos que o tornam referência para a entrada no Ensino Superior no país, assim como se apresenta como inovação no tocante às aberturas e às possibilidades para seu aperfeiçoamento e aprimoramento como sistema de avaliação, acompanhando o percurso de aprendizagem dos estudantes ao longo de seu percurso de escolarização no ensino médio. 
$\mathrm{O}$ artigo, "As possibilidades do uso dos resultados do SPAECE para subsidiar a gestão pedagógica e a aprendizagem discente numa escola de ensino médio no Ceará”, de autoria de Lucia Kelly Souza Menezes, da Secretaria da Educação do Estado do Ceará, Marco Aurélio Kistemann Junior, da Universidade Federal de Juiz de Fora e Luisa Gomes de Almeida Vilardi, da Universidade Federal de Juiz de Fora, apresenta os resultados de uma pesquisa que investigou as possibilidades de utilização pedagógica dos resultados do Sistema Permanente de Avaliação da Educação Básica do Ceará (SPAECE), visando à melhoria da aprendizagem dos alunos do $1^{\circ}$ ano do ensino médio em uma escola estadual localizada no município de Aratuba (CE). Como principal resultado a pesquisa sinalizou para a necessidade de um Plano de Ação Educacional (PAE) com ações voltadas para o estabelecimento de uma cultura de apropriação e uso dos resultados do SPAECE, bem como a formação continuada docente na temática da avaliação educacional, além de propor a realização de oficinas de apropriação de resultados e elaboração coletiva das ações de intervenção que promovam a aprendizagem discente.

Leandra Cristine Pianco da Silva, pesquisadora do Grupo de Estudos de História Sócio Cultural da América Latina da Universidade de Pernambuco, GEHSCAL-UPE, em seu artigo "Avaliação Institucional Participativa como instrumento de autonomia no fortalecimento da gestão democrática escolar", apresentou o resultado de uma pesquisa em escola pública e trouxe a Avaliação Institucional Participativa como objeto de estudo, buscando investigar os mecanismos dessa com base no viés participativo e sua relação com a autonomia no fortalecimento da Gestão Democrática. A autora verificou, com a realização da pesquisa, que a Avaliação Institucional Participativa se configura como um mecanismo de participação, enquanto exercício de autonomia na melhoria da qualidade almejada pelos atores escolares, fortalecendo a Gestão Democrática na medida em que contribui para a emancipação dos sujeitos.

No artigo, "Entre a Regulação e o Modelo Democrático: reflexões sobre a territorialização das políticas públicas de avaliação da Educação Superior”, Christine Veloso Barbosa Araújo, da Universidade Federal de Minas Gerais, refletiu sobre as transformações políticas que modificaram a relação do Estado com a Educação Superior, bem como os mecanismos de avaliação. O trabalhou apresentou reflexões sobre a territorialização das políticas públicas de avaliação da Educação Superior, buscando questionar como agem os atores locais para implementá-las a partir das competências que desenvolvem e das interações que estabelecem com os sistemas políticos, profissionais e sociais, transitando entre a 
Regulação e o Modelo de Avaliação Democrática. Segundo a autora, os resultados apontam para o desafio de convivência entre os Modelos de Regulação e Democrático.

No artigo, "Gestão Universitária: a relação entre as características do Corpo Docente e o desempenho Discente”, Alyne Alves Trindade, Jose Geraldo Pereira Barbosa e Marco Aurélio Carino Bouzada, todos da Universidade Estácio de Sá, analisaram, por meio de regressões múltiplas, a relação entre 7 fatores característicos dos docentes e o desempenho dos discentes medido a partir do Exame Nacional de Desempenho de Estudantes (ENADE) e Indicador da Diferença entre os Desempenhos Observado e Esperado (IDD). A pesquisa com abordagem quantitativa coletou dados de 63 cursos/campi nas bases de dados do Instituto Nacional de Estudos e Pesquisas (INEP) e da Universidade Estácio de Sá (UNESA). DE acordo com os autores, os resultados da pesquisa indicam a relevância de iniciativas de: (i) valorização dos professores com titulação de doutor, (ii) melhoria do processo de orientação de trabalhos de conclusão, (iii) gerenciamento da experiência no magistério (idade) e (iv) análise e reflexão sobre os resultados da avaliação da prática pedagógica, com a finalidade de melhorar o desempenho dos discentes.

Acreditamos que os artigos aprovados para compor o dossiê contribuirão para ampliar as reflexões e fortalecer o campo das políticas de avaliação externa, principalmente nesses tempos em que a questão da qualidade da educação e da escola pública tem sido cada vez mais necessária. Enfim, desejo que a leitura dos textos do presente dossiê suscite novas reflexões e profícuos debates.

Aos autores, pareceristas, revisoras e à comissão editorial da Revista Educação e Políticas em Debate, agradeço pelas valiosas contribuições, pela competência ao longo da organização que tornaram possível a concretização deste Dossiê.

\section{Referências}

AFONSO, A. J. Estado, políticas educacionais e obsessão avaliativa. Revista Contrapontos, Itajaí, SC., v. 7, n. 1, p. 11-22, mar. 2009. ISSN 1984-7114. Disponível em: https://www6.univali.br/seer/index.php/rc/article/view/888. Acesso em: 23 de junho 2020.

AFONSO, A. J. Avaliação educacional: regulação e emancipação. 2 ed. Cortez Editora: São Paulo, 2000.151 p.

BRASIL. Ministério da Educação. Fundo Nacional de Desenvolvimento da Educação. Plano de Desenvolvimento da Educação. Plano de Metas Compromisso Todos pela Educação. Guia de programas. Brasília, DF, jun., 2007. 
COSTA, M S F P M. Avaliação Institucional no Ensino Fundamental: a participação dos estudantes. Tese (Doutorado em Educação). Faculdade de Educação, Universidade Estadual de Campinas. Campinas, SP: [s.n.], 2012.

DOURADO, L.F; OLIVEIRA, J.F; SANTOS, C. A. Qualidade da educação: conceitos e definições. Instituto Nacional de Estudos e Pesquisas Educacionais Anísio Teixeira (INEP). Brasília, v. 2, n. 24, p.5-23, 2007.

ENGUITA, M. F. O discurso da qualidade e a qualidade do discurso. In: GENTILI, P.; SILVA, T. T. (Org.). Neoliberalismo, qualidade total e educação. Petrópolis: Vozes, 1997. p. 93-1 10.

FREITAS, L. C. A reforma empresarial da educação: nova direita, velhas ideias. / Luiz Carlos de Freitas. - 1.ed. - São Paulo: Expressão Popular, 2018. 160 p.

FREITAS, L. C. Eliminação Adiada: novas formas de exclusão introduzidas pelas reformas. Pro-Posições, v.16, n. 3, set./dez. 2005 a.

FREITAS, L. C. Qualidade Negociada: Avaliação e Contra-Regulação na Escola Pública. Educ. Soc., Campinas, vol.26, n. 92, p. 911 - 933, Especial - Out. 2005 b.

FREITAS, L. C. et al. Avaliação Educacional: caminhando pela Contramão. Rio: Vozes, 2009.

GENTILI, P.; ALENCAR, C. Educar na esperança em tempos de desencanto. Petrópolis: Vozes, 2005.

RAVITCH, Diane. Vida e Morte do Grande Sistema Escolar Americano: como os testes padronizados e o modelo de mercado ameaçam a educação. Tradução de Marcelo Duarte. Porto Alegre: Sulina, 2011.318p.

SORDI, M. R. L. Razões práticas e razões políticas para defender processos de avaliação institucional nas escolas de ensino fundamental. In: SORDI, M.R.L.; SOUZA, E. A avaliação institucional como instância mediadora da qualidade da escola pública: a Rede Municipal de Educação de Campinas como espaço de aprendizagem Campinas: Millenium, 2009.

SORDI, M. R. L. e LUDKE, M. Da Avaliação da Aprendizagem à Avaliação Institucional: aprendizagens necessárias. In: SORDI, M.R.L.; SOUZA, E. A avaliação institucional como instância mediadora da qualidade da escola pública: a Rede Municipal de Educação de Campinas como espaço de aprendizagem. Campinas: Millenium, 2009. 